\title{
Making the best of it: Adolescents' perceptions of how their home and neighbourhood spheres shape their lives
}

\author{
Vibeke Krane * \\ Center for Social Entrepreneurship and Social Innovation \\ University of South- Eastern Norway. \\ E-mail: vibeke.krane@usn.no \\ *corresponding author

\section{Ellen Andvig} \\ Faculty of Health Sciences \\ University of South- Eastern Norway, Drammen, Norway \\ E-mail: Ellen.Andvig@usn.no
}

\begin{abstract}
Adolescents' homes are fundamental components of their living conditions and essential for their everyday life, health, well-being and development. Previous research has focused on how housing affects adolescents through investigating certain aspects of adolescent health and future outcomes. In this qualitative study, we explored lowincome family adolescents' subjective experiences of their homes and in what ways their experiences of housing influenced their everyday lives. Seven participants aged between 12 and 20 years were recruited through a housing project. The participants were interviewed using individual in-depth interviews. The data were analysed using a thematic analysis and organised into four themes: 1) housing features affecting social life and privacy, 2) moving around, 3) the importance of neighbourhood and 4) worries and dreams. The findings show how the housing standards affected adolescents' social life and privacy. House moves could provide new opportunities but also lead to a lack of continuity in relationships. The neighbourhood was highlighted as a public sphere, providing access to places and friends. Adolescents' worries and dreams concerning housing conditions are also presented. The results show how housing is central in shaping adolescents' social relationships, the importance of access to neighbourhood spheres and how adolescents adapt to their situation. The findings further reveal the important underlying processes to facilitate a greater understanding of the role of housing in low-income family adolescents' lives.
\end{abstract}


Keywords: adolescent, low income, housing, social relationship, subjective experience

\section{Background}

Children and adolescents spend more time in the home environment than in any other physical setting. Thus-and in line with an ecological perspectivechildren's and adolescents' homes are fundamental components of their living conditions and are crucial experiences of their environments as they grow up (Bronfenbrenner \& Morris, 1998). The United Nations Convention on the Rights of the Child (1989) Article 27 states, 'The right of every child to a standard of living adequate for the child's physical, mental, spiritual, moral and social development'. Article 27 further elaborates that children's rights involve the living conditions and housing necessary for the child's development. These rights are an acknowledgement of children's and adolescents' homes as an essential prerequisite for their positive development.

'Home' has been defined as the location where people are settled psychologically, socially, culturally and physically, involving both symbolic and emotional aspects (Hauge, 2009, p. 28). Hayward (1977) identifies the core dimensions of meaning that are considered home: self-identity, close relationships, a social network, a place of privacy and refuge, continuity, a personalised place, a base of activities, the childhood home and a physical structure.

Because of the digital revolution and social media, Norwegian adolescents spend more time at home in their spare time (Bakken, 2019), making the home an even more central area of their lives. During the Covid-19 pandemic, there is also a huge shift toward doing more at home as well. In recent decades, housing has received growing attention from social scientists as an important context for children's and adolescents' lives (Clair, 2018; Coley et al., 2013; Leventhal \& Newman, 2010). A distinction is frequently made in housing research between two perspectives of the home, that is, between interactions in the household and the house itself (Leventhal \& Newman 2010). Traditionally, the child development literature focusing on the home environment has explored the interactions and experiences that are available to the child in the home. The second focus in this stream of literature concerns the effect of the house itself, as captured by the physical, financial and practical features of the home (Leventhal \& Newman, 2010). However, there is a dynamic interplay between the condition of the house itself and the interactions in the household, and these concepts are interconnected. Housing 
is also related to other aspects of living conditions and operates as a type of gatekeeping mechanism in facilitating or inhibiting access to neighbourhood public services, such as schools, public transport, health and social services (Clair, 2018). In this respect, the home represents a physical structure that regulates and defines the relationship between the adolescent and society. In the current article, we will use the terms 'house' and 'house standard' to refer to the material house. The term 'household' will be used to refer to the house and its occupants as a unit. The term 'home' will be used as a concept to cover the material, social, relational and emotional dimensions related to housing.

\section{The Norwegian housing context}

Norway has been described as a 'homeowner nation' (Vassenden et al., 2012). Close to $80 \%$ of households in Norway comprise houses that are owner occupied or cooperatively owned (Sandbæk, 2013). However, lowincome families are far less likely to own their homes. Families with an income below $60 \%$ of the national median income are commonly classified as lowincome families (Omholt, 2016). Those who are not homeowners have to enter the private rental market because there is very limited availability of social housing, with only $4 \%$ of Norwegian house stocking being publicly owned (Sandlie \& Gulbrandsen, 2017). Social housing is reserved for the socially and economically worst-off (Hauge, 2009), and there is a strong association between low-income and poor households. The number of children growing up in low-income families in Norway has increased over the past decade, with approximately $9-10 \%$ of Norwegian children being raised in low-income families (Povlsen et al., 2018). Low-income families are more likely to experience poor housing conditions, which includes cramped living conditions where children less likely to have their own rooms and more financial worries (Omholt, 2016; Sandbæk, 2012). Low-income families are often socially stigmatised and regarded as unattractive tenants (Vassenden et al., 2012); this often results in residential mobility, with frequent moving being more common among these low-income families.

\section{In what ways does housing affect adolescents' lives?}

Numerous housing studies have found that adolescent health and outcomes are affected by various housing-related aspects, such as physical housing quality, overcrowding, residential mobility and the type of neighbourhood (Clair, 2018; Leventhal \& Brooks-Gunn, 2000; Leventhal \& Newman, 2010). 
Poor physical housing quality is usually measured in terms of structural deficiencies, such as a lack of plumbing and heating, and maintenance deficiencies and dampness, along with the presence of bugs, dust mites and rats. Numerous studies have explored the effects of poor housing quality on children's physical health (Leventhal \& Newman, 2010). A limited number of studies has shown how housing quality may indirectly influence children's development by contributing to negative family interactions in terms of increased stress and conflict among family members. Evans et al. (2001) find an association between poor quality houses and socioemotional functioning and psychological symptoms among children and adolescents. Moreover, poor quality housing has been associated with reduced educational outcomes, especially among adolescents (Coley et al., 2013). Other studies have shown that improvement in housing quality is associated with improvements in school achievement and lower dropout rates for adolescents (Haurin et al., 2012).

Overcrowding relates to the number of rooms available to individual members of a household, where a ratio greater than one person per room is considered evidence of overcrowding (Leventhal \& Newman, 2010). Overcrowding involves a lack of personal space or privacy, or enforced intimate proximity to other people in the home and disturbed sleep. Numerous studies have shown a relationship between overcrowding and children's poor physical health. Some studies have also found a relationship between crowded housing conditions and emotional and behavioural problems among children (Coley et al., 2013; Leventhal \& Newman, 2010). Moreover, studies have found associations between cramped housing conditions and educational outcomes, with children living in crowded houses having lower educational achievements and lower levels of completed schooling, with adolescents having their own rooms showing better educational outcomes (Clair, 2018; Leventhal \& Newman, 2010).

The neighbourhood effects on child and adolescent outcomes have been widely explored in the social sciences, but there is no consensus on the effects because these are intertwined with individual and family variables in complex processes. A review of neighbourhood effects has shown a link between neighbourhood socioeconomic standards (SES) and educational achievement, behavioural problems and juvenile delinquency (Leventhal \& Brooks-Gunn, 2000). A study by Sarti et al. (2019) finds that children from poor families actively make use of public spaces in their outside environment to shape their daily lives and development to ensure that financial strains, even though present, can be managed. In a Swedish context, significant 
neighbourhood effects have been identified in relation to school choice and children's prospects of work and a well-paying career as an adult (Malmberg et al., 2014). A Finnish study has explored the impact of neighbourhoods on parents' subjective well-being (Poikolainen \& Honkanen, 2020), finding that parents emphasised the natural environment, social networks and well-being and safety of their children in the neighbourhood as important components for their own subjective well-being.

Residential mobility, or home moves, refers to the frequency with which families move their residence. The impact of home moves on children and adolescents has been explored in several studies (Clair, 2018; Gambaro \& Joshi, 2016; Leventhal \& Newman, 2010). The findings suggest that moving affects children in different ways, depending on their age, the timing of the move and family structure. Behavioural problems, poorer mental health and lower experiences of well-being have been associated with home moves (Clair, 2018). Moving may lead to school change and a lack of continuity in schooling, which can cause problems in educational achievement and school dropout (Leventhal \& Newman, 2010). However, for some adolescents, positive effects may arise because of moving, for example, to a 'better' neighbourhood or to better-quality housing (Clair, 2018). Frequent moves are typically described as residential instability, and it has been reported that adverse outcomes are likely to increase in relation to a rising number of moves (Leventhal \& Newman, 2010; Gambaro \& Joshi, 2016).

Taken together, a growing body of research has found associations between housing standards and the health, deficits, problems and outcomes of children (aged 0-11) and adolescents (aged 12-19) (Clair, 2018; Leventhal \& BrooksGunn, 2000; Leventhal \& Newman, 2010). These studies show that children and adolescents from low-income families are far more exposed to poor physical housing quality, overcrowding, poor neighbourhoods and residential mobility. However, most of these studies have used a quantitative design and involve statistical associations found between housing features and future outcomes for children and adolescents. Because children's outcomes are the result of complex processes, these associations cannot be understood as causal. Hence, qualitative studies are suitable for shedding light on some of these complex processes, yet qualitative studies exploring adolescents' subjective perspectives on housing and their everyday lives are rare. Moreover, there are few studies covering the Nordic housing context for adolescents. 
In the current study, we have focused on how seven Norwegian adolescents from low-income families experienced housing and how it has affected their everyday lives. To shed light on some of the complex processes involved in relation to housing and adolescents' lives, we chose a qualitative design. To explore these issues, we raised the following research question: How does low-income family adolescents experience the influence of housing on their everyday lives?

\section{Methodology}

\section{Study context}

For the present study, the participants were recruited through an innovation housing project running from 2018 to 2020 in a middle-sized Norwegian town. The projects' aim is to develop and pilot new strategies in relation to housing solutions for low-income families living in difficult housing conditions. The project manager recruited the participants through their parents, who participated in this project.

\section{Methods}

The present study has a qualitative, explorative and interpretive design, here aiming to capture the subjective experiences of adolescents concerning housing. Individual qualitative interviews were used to collect data. Such indepth interviews are useful in exploring an individual's subjective experiences (Brinkman \& Kvale, 2015). The study takes a hermeneutic stance, which acknowledges that meaning emerges through interpretive interactions and that phenomena are always multidimensional and multifaceted (Crotty, 1998).

Seven adolescents were included in this study. Adolescents from the seven low-income families who participated in the housing project were asked to participate. The inclusion criteria involved participants aged between 12 and 20 years old and who were living in difficult housing conditions, and whose parents were involved in the housing project.

The first author was the interviewer; she used a thematic interview guide to ask questions in relation to experiences of home, neighbourhood, moving, friends, school and the relevant financial situation. The interviews took place in the period from 2018 to 2019, and six interviews took place in the participants' homes. The seventh interview took place at the housing project's office. The interviews lasted from 30 to 70 minutes. The interviewer explained the purpose of the interviews and highlighted the importance of the participants 
expressing their own experiences and perspectives. The interviews were open ended, and the interviewer encouraged the participants to speak freely.

\section{Analysis}

The interviews were transcribed verbatim. The transcribed text was analysed inductively, aiming to grasp the participants' subjective experiences, here by using a thematic analysis (Braun \& Clarke, 2006). The inductive approach had a bottom-up perspective, where the themes were extracted from the data. In this respect, the themes can be understood as recurring patterns that grasp the participants' experiences.

Both authors read all the transcripts to become familiar with the data, noting their initial thoughts, ideas and emerging themes. Subsequently, the material was separately coded line by line by the two authors using the research questions as a guide. Meaningful elements such as quotes and descriptions of the emerging themes were identified, listed, organised and sorted into tentative themes. The tentative themes were discussed between the two authors and then revised. The data were examined and discussed with the authors several times to complete categorisation into four main themes.

\section{Ethics}

In accordance with the Personal Data Act, the Norwegian Social Science Data Services (NSD) was notified, and approval for the project was granted. Parents and participants were informed of the purpose of the study through written and oral information provided by the leader of the housing project. The implications of participation were explained, and the requirements for voluntary participation was underlined. Written consent for participation from the participants and the parents of those under 16 years old was obtained. The participants were paid 200 Norwegian kroner (NOK) for their participation as compensation for their effort and time spent in the interview. This payment was approved by the NSD. The first author, who has received specialised education and training in interviewing children, interviewed the participants. It is of special ethical importance to be aware of how to interview children to avoid potential harm (Morrow \& Richards, 1996). Personal details and names have been changed in this article to ensure confidentiality.

\section{Participants}

Ari was 13 years old and lived with his mother and older sister. He had been living in his current home, a social housing unit, for two to three years. Ari and his sister had their own rooms, but their mother had to sleep in the living room. 
He had moved around a lot between different municipalities and had also lived in foster care for some years.

Beatrice was 13 years old and lived with her mother and older sister. Her grandparents lived abroad, and Beatrice was born and lived the first year of her life in the country where her grandparents lived. Both Beatrice and her sister had their own rooms. Her father had recently moved to the same district as Beatrice.

Lila was 12 years old and living with her parents and older brother. She also had two adult siblings who visited and stayed overnight quite frequently. She shared a room with her older brother and her two adult siblings when they came to visit. The family came to Norway as refugees. She had lived in the same house for six years and could not remember where she lived before that.

David was 17 years old. He lived part time with his father and part time with his mother, swapping homes every other week. In total, he had seven siblings, including half-siblings and step-siblings in both homes. He had moved around a lot and was not sure how many times he had moved. His father's house was spacious, and each of the children had their own room. His mother's various houses had been crowded and in bad condition.

Eve had just turned 20 years old and was David's older sister. She used to swap homes every other week during her childhood, whereas now, because she was an adult, she swapped houses when she felt like it. She always had her own room in her father's house. At the time of the interview, she was sleeping in the hallway in her mother's new house.

Amber was 14 years old and lived with her mother and three younger siblings. The family came to Norway as refugees approximately six6 years ago. She moved from her country of origin to a nearby country and ha moved twice in Norway. At the time of the interview, she had her own room.

Malika was 12 years old and Amber's younger sister. She used to share a room with her siblings, but at the time of the interview, she had a room of her own. She could vaguely remember that she lived somewhere in transit as a refugee. 


\section{Findings}

The thematic analyses generated four overarching themes: 1) housing features affecting social life and privacy, 2) moving around, 3) the importance of neighbourhood and 4) worries and dreams.

\section{Housing features affecting social life and privacy}

All participants described how housing features and the quality of the house affected their social life. They described how the layout of the house facilitated or inhibited socialising and interactions with both family and friends. They also highlighted the importance of having privacy and space for themselves.

\section{Spending time with family}

Some of the participants talked about how they appreciated spending time with their family in their home environment. Beatrice explained how she experienced the open-plan style of her house: 'I think it is more fun when it's open plan because then you can talk to each other instead of shouting to each other between the rooms'. Lila described how she spent time with her family in their living room: "I think family life is really good... we sit together and watch TV series together... one new episode each day....'

However, the participants also gave reasons why the standard of housing could inhibit socialising with friends. Ari admitted, 'I am embarrassed ... I think it is really old fashioned and I want it to be more up to date... and we only have two bedrooms, it is really small... so I never bring friends home'. David disclosed how he never invited friends to a house he used to live in: 'I did not bring any friends over... because it was rather crowded.... I think they would have wondered why we had such a small house when we were so many people...'.

Having privacy and being able to socialise in their own room

All the participants highlighted the importance of having their own room. They emphasised how their room was a place to withdraw to and have some privacy, but also a place to socialise in and invite friends to.

Based on experiences during her childhood, Eve explained the following:

I think when you are a family as large as ours it is important to find a house which has enough rooms for everybody.... We lived in a house where my brother and I shared a room. The room was big..., but we were supposed to share it.... It did not provide much privacy. My stepdad made two walls.... And we slept on each side of the walls.... So it is possible to do something about it... But if my brother fell asleep before me and I was awake it was like 'sssshhh'.... So it could easily turn into a quarrel. 
Malika said, 'If you want to be alone... you can hang out there (in her room).... I am not there always but if I am annoyed with my siblings I can go there...'.

Their rooms could also be places to spend time together with friends. Some of the participants described how their parents arranged their rooms to facilitate socialising with friends. Beatrice commented, 'So my room is really nice, and I am glad I got the largest room because I have more friends coming over'. Ari explained how they had arranged the rooms in their apartment: 'My sister has her own room, and I have one too now. My mum and I used to share a room, but I am getting older, so I wanted my own room, and now mum sleeps in the living room'.

\section{Moving around}

All the participants had moved several times, and some had moved multiple times. The participants explained how moving home could provide new opportunities and better housing. However, they also described how frequent moving could lead to a lack of continuity regarding friendships and school connectedness.

\section{Home moves provide new opportunities}

Several of the participants described how they looked forward to moving because they thought it would lead to better housing quality, less cramped living conditions and the possibility of having their own rooms. They also highlighted the opportunity that moving provided to live in a better neighbourhood. Some of the participants described how moving was undertaken in an attempt to escape from bullying.

Amber looked at moving as an opportunity to move away from their current neighbours, who constantly complained about them: 'I think moving is kind of fun... it will be a new home... and then the neighbours will stop complaining at us'. Lila had hopes for a room of her own: 'So mum and dad are trying to find a house... so we can move. And then I will get a room of my own'.

Beatrice discussed her experience of bullying and how moving away had helped: 'Sometimes I came home crying, because I was bullied. But when I started at the school I attend now I felt that I would be more at home... and I do... I am OK here ... I still get bullied, but not much .... And I feel more relaxed here in this house ...'. Eve moved multiple times, explaining, '... we moved from our last home because of the young ones. Maybe they will get better friends here ... that is why we moved to a new neighbourhood'. 
Home moves lead to a lack of continuity

All the participants had been to more than one primary school because of moving, and some had attended multiple schools. They described how this situation had led to a lack of continuity in friendships, with some of the participants describing how it had been difficult to blend into new neighbourhoods and different schools, leading to issues of bullying.

David explained how he had experienced the effect of multiple moves on friendships: 'It is kind of annoying not living in the same place for a long time... You don't get time to know the neighbourhood if you move around all the time... you don't get time to get friends in the area and things like that...'

Ari described how it had been difficult for him to get friends:

\begin{abstract}
....and I moved back to mum. I went to one school for a while, but I didn't feel good there. ... I did not have any friends there and I felt that they bullied me... so we moved, and I started at a different school.... I was there only for a couple of months... and then I went to a third school.... But I don't spend time with my friends in my spare time because they are not allowed by their parents to spend time with me..
\end{abstract}

\title{
The importance of neighbourhood
}

The participants highlighted their neighbourhoods as important settings in their everyday lives. They described how they appreciated that their neighbourhoods gave them access to both nature and towns where they could spend time and participate in activities. They also emphasised the importance of having friends living in their neighbourhoods.

\section{Access to nature, towns and places of entertainment}

Several of the participants described how they appreciated living close to nature and how they spent time in diverse locations. Both Amber and Malika described how they went for evening walks in locations close to their house. Malika said, 'I like walking around.... We go for an evening walk to a viewpoint over there.... It is fun.... And wonderful ... fresh air in the evening... and it is so quiet... and we take pictures when there's a sunset...'

Beatrice described how she appreciated that her house lay close to a forest: 'I love the forest. Sometimes I just like to go out and look at the forest, and I think it is neat that the way to secondary school goes through a forest... there is a path...'. 
The participants also appreciated how their homes were close to town, to varying possibilities of entertainment and to school. Ari explained that he valued his home being close to many interesting places in town: 'It is really close to things; the cinema, the beach. It is really nice here. It is neat to walk in the narrow streets. I really like living in this neighbourhood'.

Lila stated, 'I really like it very much here.... It is in the middle part of the street.... I can cycle around ... and there is a shop close by ... and it is really close to school...'.

\section{Closeness to friends}

The participants also highlighted the importance of living close to other children and friends. However, closeness to friends appeared to be more important for the adolescents when they were younger.

Beatrice explained, 'I think it is important that children live next to each other... because then they can play together. When I lived in that other house, there were many children living close by... I liked it...'.

David explained why he preferred to be at his father's place: 'Where dad lives it is only 5 to 7 minutes to my friends-it is better, instead of going really far to meet my friends'. Ari explained how he found it challenging to live far away from friends: "I live quite far away... and it takes a long time getting to school, and if my friend who lives close to school should think of planning something together... we don't bother... so I can't be part of that'.

\section{Worries and dreams}

All the participants expressed some worries about their housing conditions. In contrast to their worries, all the participants had detailed descriptions in relation to how their dream houses should be laid out.

\section{Worrying about housing conditions and the economic situation at home} The participants had experienced cramped living conditions or houses infested with bugs, mice and other pests. Several of the participants described how they shared their parents' financial worries and concerns about the housing standards.

Lila explained how she was worried about the state of the electricity in the house she lived in: 'It happens frequently that the light goes out.... Some time 
ago, we heard a loud sound like a bomb, and we got really scared... and it was black in the light socket... it was really dangerous'.

Eve described how their last house had been in bad condition: 'In the basement... it was full of woodlice... and things like that. Bad quality... and on the first floor it was really cold and draughty'.

Amber found it challenging that they had complaints from the neighbours: 'If we make just a small sound, everybody can hear it... and they start complaining'. Her sister Malika said, 'We have to take care... only speak in a low voice... we can't speak as loud as we want to...'.

Ari explained why he worried about their cramped house: 'I have really guilty conscious ... I think I have it all the time.... I get that easily... I have a guilty conscious because mum has to sleep on the sofa in the living room... I want her to have her own room'.

Beatrice described her family's financial worries: 'Money is a bit difficult... mum has to pay for this house... she has to pay all the bills: water bills, internet bills and all that.... And it is difficult... we also need money for food.... I don't think too much about it, but I don't know about mum...'. Ari said, 'I know that mum don't have enough money for everything I ask for ... and I ask for a lot of things....'

David revealed, 'I worry a lot about costs... I often ask dad 'How are you doing now?' Do you have any money now'? If I need something, football shoes or gloves or something... I don't ask him when he doesn't have money'.

\section{Their dream houses}

The participants were asked what the house of their dreams would look like. They all had strikingly detailed descriptions of this house, and some of them said that they had constructed their dream house several times in computer games. All the participants highlighted that their dream house should be spacious, include a room for each child in the family, and that it should have a nice garden and swimming pool.

Amber said, 'This is just a dream house... but it should have a swimming pool and a place for a barbecue and a big garden.... And at least five bedrooms ... one for each child ... because then we wouldn't have to argue'. 
Lila expressed her wish as follows: 'I would like a room of my own... all mine.... And a big swimming pool outside and a balcony and two floors'.

Malika had a more modest wish for her room: 'I would like my own closet ... because now I share it with Amber... she has a closet in my room'. However, she also dreamed of a big house: 'I would have two floors... and outside I would like to have a swimming pool...'.

\section{Discussion}

In this section, we discuss the findings of adolescents' subjective experiences of their home and how housing influenced their everyday lives in terms of how housing is important in shaping social relationships, the importance of access to differing neighbourhood spheres and how adolescents adapt to their situation.

Whereas most of the research on housing has focused on adolescents' health, deficits, problems and future outcomes, the participants in our study were more concerned with how the home environment facilitated social interactions and relationships. The findings show how the physical outlay of the house, residential mobility and type of neighbourhood sphere could, in combination, act to facilitate or inhibit social interactions and relational development. Several studies have focused on how cramped living conditions can affect children's and adolescents' physical health and educational performance (Clair, 2018; Leventhal \& Newman, 2010), whereas our participants were more concerned with how the cramped living conditions affected their social life. Our findings underline how the home is a key component of the microsystems influencing the lives of adolescents, showing how the home might promote or inhibit social interactions, both within the family and with peers. This finding is also in line with research pointing to 'close relationships' and 'social networks' as some of the core dimensions in the concept of home (Hayward, 1977). Some of the participants described how they did not bring friends home because they were embarrassed by their house. The findings show how bad and cramped housing conditions in low-income families can inhibit social interactions with friends for adolescents. This finding is in line with that of Sarti et al.'s (2019), showing how the physical conditions of a house can inhibit the development of social interactions and relationships with peers at home. The importance of having enough space and a room of their own was highlighted by all the participants in their descriptions of their current house, as well as in their 'dream house'. Their own room was viewed as a place to invite friends and develop social relationships, but also as a place to 
withdraw to and regulate closeness and distance in family life. Both the development of social relationships and having personal space are important aspects of youth development. Adolescents who do not have their own room form a small minority in Norway (Sandbæk, 2012). Furthermore, there has been a development over the past decade in which children and adolescents in Norway are spending more time at home (Bakken, 2019). Our findings underline how the quality and physical outlaying of the house are essential in adolescents' possibilities to establish and develop social relationships. This shows how the home has a paramount role in adolescents' lives by tying together space, relationships and daily living.

The participants described how frequently moving could be challenging because they had to develop new social relationships and adapt to new schools. Clair (2018) states that the negative consequences of home moves are more prevalent for adolescents, becoming more pronounced with advancing age. It has been suggested that residentially mobile adolescents may have particular difficulty gaining acceptance into prosocial and highachieving friendship networks because of a resulting decrease in social capital (Haynie et al., 2006). In our study, several participants spontaneously revealed that they had been exposed to bullying. Social support and positive relationships with peers and teachers have been identified as protective factors against the negative consequences of bulling (Breivik et al., 2017). Because residential instability makes it difficult to establish and maintain such stable relationships, adolescents who move often may be especially vulnerable to bullying. Thus, the challenges around fitting into a new school and developing new peer relationships may be especially important to understand as the underlying mechanisms that can lead to such negative consequences following moving.

In our study, the participants described how they engaged in the public spheres in their neighbourhoods. This finding is in line with the findings of other studies, where children living in cramped living conditions and poverty are actively using public spheres and that this engagement may compensate for deficiencies at home (Sarti et al., 2019). An important issue identified by the participants was the need to live close to their friends. The social environment and possibility for their children to easily make friends have also been highlighted as important positive neighbourhood features by parents (Poikolainen \& Honkanen, 2020). This finding shows that the neighbourhood works as a type of gatekeeping mechanism in forming and maintaining social relations. The social life of children and adolescents unfolds in their local 
context, which is supported by research on socialising processes involving children and adolescents linking such processes to the situated and geographical context where they grow up (De Visscher et al., 2012). This finding underlines the importance of public spheres in providing not only access to experiences of nature and range of activities, but also for facilitating socialising with peers.

Some of the participants in the current study had experienced living in bad physical conditions, involving mould, dampness and bugs. Studies in a Norwegian context have shown that cramped living conditions and problems with heating and noise are more common in social housing (Skog Hansen \& Lescher-Nuland, 2011; Brattbakk et al., 2015). Poor-quality housing has been associated with adolescent emotional and psychological problems (Coley, 2013; Evans, 2001). The participants in our study did not have specific emotional or psychological problems. However, some of them expressed some worries concerning their parents' financial challenges. This finding is in line with other studies that also show that children from low-income families tended to be aware of the financial challenges and housing problems facing the family (Clair, 2018; Sarti et al., 2019). In line with our study, the children in these situations were reported as wanting to protect their parents by adapting to the situation. This behaviour may be an indication of a willingness of children and adolescents to adapt and suppress the expression of their needs and wishes for material goods to protect their parents (Thorød, 2008). However, the participants also described how their parents sometimes made specific arrangements for their benefit. It is also worth mentioning that several of the participants did not mention any financial worries.

In the present study, the participants displayed positive and optimistic views toward the home and housing. Despite revealing some worries about certain challenges with poor housing quality, cramped living conditions and frequent moving, the participants seemed to highlight the positive sides of their housing conditions, describing how they were coping and trying to make the best of their situation. These findings are in line with Sarti et al.'s (2019) findings, which show, perhaps counterintuitively, that children from poor families were quite optimistic and positive about their lives. The optimistic attitudes indicated that the participating adolescents appeared to be coping and were resourceful in their response to their situation in terms of how they interpreted their surroundings. These findings are in contrast to the unidirectional negative effects of low income on adolescents' well-being that are generally presented 
in the relevant literature, illustrating how deficiencies and resourcefulness could go hand in hand.

\section{Limitations and strengths}

A strength of the current study is the participants' age span and diversity of cultural backgrounds. This may contribute to the variation and trustworthiness of the data. The older participants contributed with both retrospective perspectives from their childhood and current perspectives on their own and younger siblings' experiences. The younger participants brought in their present perspectives. The participants' diverse cultural backgrounds reflect the high number of immigrants among low-income families. Their cultural background was not a specific focus for the interviews; however, we were struck by the similarities of the adolescents' perspectives across cultural backgrounds. A limitation in using in-depth interviews as a data collection method for exploring the participants' experiences lies in how this approach is suitable for grasping 'true lived experiences'. Stories shared in interview settings are always a product of the interaction between the interviewer and participant (Klevan et al., 2016). In the present study, the adolescents were rather brief in their explanations and story sharing. However, a strength is the first authors' special education and experience in working with adolescents; indeed, her broad experience in interviewing adolescents may have led to richer dialogues.

\section{Conclusion}

The current study has shown how exploring low-income family adolescents' own perspectives on housing revealed a resourcefulness among these adolescents, further underlying the processes that are important to their development and current well-being. The adolescents described their home and neighbourhood sphere first and foremost as a prerequisite in developing social relationships. The current study has revealed in-depth insights lowincome family adolescents' perspectives on how the housing standards and location of their home and neighbourhood are directly associated with their social lives. These findings support the children's rights elaboration of how adequate housing is essential for children's and adolescents' social development (The United Nations Convention on the Rights of the Child, 1989). Moreover, the findings are a contribution to existing housing studies that mainly focus on deficits and future outcomes for adolescents. 
Future research on housing for low-income families should explore how to involve adolescents' perspectives in finding solutions to difficult living conditions.

The current study underlines the importance of exploring the everyday lives of adolescents from low-income families in a contextual way; specifically, there is a need to look beyond family interactions and explore the relevant contextual factors and how these influence adolescents' lives. Policy makers and social and child welfare services should be aware of how cramped houses, residential instability and the quality of neighbourhood spheres available influence adolescents' possibilities to develop and maintain valuable social relationships. This calls for public investments and new solutions to ensure low-income families have access to decent, stable and affordable homes. By listening to the adolescents and facilitating the provision of adequate housing, it is likely that it will be possible to promote more stable relationships and better social support, which, as the evidence strongly indicates, are factors that are essential to their development and well-being.

\section{Acknowledgements}

This study was founded by the University of South-Eastern Norway with support from the Norwegian State Housing Bank. The authors would like to thank the participants for contributing to this study through sharing their stories.

\section{References}

Bakken, A. (2019). Ungdata . Nasjonale resultater 2019 [Ungdata. National results 2019]. NOVA Rapport 9/19. NOVA, OsloMet.

Brattbakk, I., Hagen, A. L., Rosten M. R., Sæter, O., Osuldsen, J., Andersen, B., Thorstensen, E., \& Bratseth, K. (2015). Hva nå, Tøyen? Sosiokulturell stedsanalyse av Tøyen i Bydel Gamle Oslo [Whats' next Tøyen?]. Rapport 8/2015. Arbeidsforskningsinstituttet. https://doi.org/10.7577/afi/rapport/2015:8

Brinkmann, S., \& Kvale, S. (2015). InterViews: Learning the craft of qualitative research interviewing (Vol. 3). Sage.

Bronfenbrenner, U., \& Morris, P. (1998). The ecology of developmental processes. In R. M. Lerner (Ed.), Theoretical models of human development (pp. 993-1028). Wiley. 
Braun, V., \& Clarke, V. (2006). Using thematic analysis in psychology.

Qualitative Research in Psychology, 3(2), 77-101.

https://doi.org/10.1191/1478088706qp063oa

Breivik, K., Bru, E., Hancock, C., Idsøe, E., Idsøe, T., \& Solberg, M. (2017). A bli utsatt for mobbing En kunnskapsoppsummering om konsekvenser og tiltak [To be exposed to bullying. A review of consequences and implications]: Læringsmiljøsenteret.

Clair, A. (2018). Housing: An under-explored influence on children's well-being and becoming. Child Indicators Research, 12(2), 609-626. https://doi.org/10.1007/s12187-018-9550-7

Coley, R. L., Leventhal, T., Lynch, A. D., \& Kull, M. (2013). Relations between housing characteristics and the well-being of low-income children and adolescents. Developmental Psychology, 49(9), 1775. https://doi.org/10.1037/a0031033

Crotty, M. (1998). The foundations of social research: Meaning and perspective in the research process. Sage.

De Visscher, S., Bouverne-De Bie, M., \& Verschelden, G. (2012). Urban public space and the construction of social life: A social-pedagogical perspective. International Journal of Lifelong Education, 31(1), 97110. https://doi.org/10.1080/02601370.2012.637417

Evans, G. W., Saltzman, H., \& Cooperman, J. L. (2001). Housing quality and children's socioemotional health. Environment and Behavior, 33(3), 389-399. https://doi.org/10.1177/00139160121973043

Gambaro, L., \& Joshi, H. (2016). Moving home in the early years: What happens to children in the UK? Longitudinal and Life Course Studies, 7(3), 265-287. https://doi.org/10.14301/llcs.v7i3.375

Hauge, A. L. (2009). Housing and identity: The meaning of housing in communicating identity and its influence on self-perception $[\mathrm{PhD}$ thesis, Norwegian University of Science and Technology ].

Haurin, D. R., Parcel, T. L., \& Haurin, R. J. (2002). Does homeownership affect child outcomes? Real Estate Economics, 30(4), 635-666. https://doi.org/10.1111/1540-6229.t01-2-00053

Haynie, D. L., South, S. J., \& Bose, S. (2006). The company you keep: Adolescent mobility and peer behavior. Sociological Inquiry, 76(3), 397-426. https://doi.org/10.1111/j.1475-682X.2006.00161.x

Hayward, G. (1977). Housing research and the concept of home. Housing Educators Journal, 4(3), 7-12.

Klevan, T., Davidson, L., Ruud, T., \& Karlsson, B. (2016). 'We are different people': A narrative analysis of carers' experiences with mental health crisis and support from crisis resolution teams. Social Work in Mental 
Health, 14(6), 658-675.

https://doi.org/10.1080/15332985.2015.1133471

Leventhal, T., \& Brooks-Gunn, J. (2000). The neighbourhoods they live in: The effects of neighbourhood residence on child and adolescent outcomes. Psychological Bulletin, 126(2), 309. https://doi.org/10.1037/0033-2909.126.2.309

Leventhal, T., \& Newman, S. (2010). Housing and child development. Children and Youth Services Review, 32(9), 165-1174. https://doi.org/10.1016/j.childyouth.2010.03.008

Malmberg, B., Andersson, E. K., \& Bergsten, Z. (2014). Composite geographical context and school choice attitudes in Sweden: A study based on individually defined, scalable neighbourhoods. Annals of the Association of American Geographers, 104(4), 869-888. https://doi.org/10.1080/00045608.2014.912546

Morrow, V., \& Richards, M. (1996). The ethics of social research with children: An overview 1. Children \& Society, 10(2), 90-105. https://doi.org/10.1002/(SICI)1099-0860(199606)10:2<90::AID$\mathrm{CHI} 14>3.0 . \mathrm{CO} ; 2-\mathrm{Z}$

Omholt, E. L. (Ed.). (2016). Økonomi og levekår for ulike lavinntektsgrupper 2016 [Economy and living conditions in low-income families 2016]. SSB.

Poikolainen, J., \& Honkanen, K. (2020). How do urban neighbourhoods impact parents' subjective well-being? Nordic Journal of Social Research, 11(1), 19-38. https://doi.org/10.7577/njsr.2198

Povlsen, L., Regber, S., Fosse, E., Karlsson, L. E., \& Gunnarsdottir, H. (2018). Economic poverty among children and adolescents in the Nordic countries. Scandinavian Journal of Public Health, 46(20_suppl), 3037. https://doi.org/10.1177/1403494817743894

Sandbæk, M. (2013). Child poverty in a rich welfare state. Child Indicators Research, 6(1), 53-69. https://doi.org/10.1007/s12187-012-9157-3

Sandlie, H. C., \& Gulbrandsen, L. (2017). The social homeownership modelThe case of Norway. Critical Housing Analysis, 4(1), 52-60. https://doi.org/10.13060/23362839.2017.4.1.324

Sarti, A., Dedding, C., \& Bunders, J. F. (2019). Beyond a deficiencies approach: Towards a more integral representation of the everyday life of children growing up in contexts of poverty. Qualitative Social Work, 18(5), 818-833. https://doi.org/10.1177/1473325018768391 https://doi.org/10.1177/1473325018768391

Skog Hansen, I. L., \& Lescher-Nuland, B. R. (2011). Bolig og oppvekst. En studie av konsekvenser av å vokse opp under vanskelige boforhold 
[Housing and growing up: A study of growing up living in difficult housing conditions]. Fafo-rapport 2011:16

Thorød, A. B. (2008). Sosial eksklusjon [Social exclusion]. In M. Sandbæk (Ed.), Barns levekår: familiens inntekt og barns levekår over tid [Children's living conditions, family- income and children's living conditions over time] (bd. 7/2008). NOVA.

United Nations General Assembly. (1989). Convention on the Rights of the Child. United Nations Treaty Series, 1577(3).

Vassenden, A., Lie, T., \& Skoland, K. (2012). Man må ha en plass å bo. En sosiologisk studie av vanskeligstilte i et boligeierland [You need a place to live. A sociological study of people in poverty in a land of home owners]. International Research Institute of Stavanger Rapport IRIS- 2012/029 